\title{
EFEKTIVITAS BADAN KEAMANAN LAUT DALAM MELAKSANAKAN FUNGSI PENEGAKKAN HUKUM DI PERAIRAN LAUT INDONESIA
}

\author{
Suradi Agung Slamet ${ }^{1}$, Aries Djaenuri ${ }^{2}$, Khasan Effendy ${ }^{3}$, Sampara Lukman $^{4}$ \\ ${ }^{1,2,3,4}$ Institut Pemerintahan Dalam Negeri (IPDN) \\ Email:soeradi_as@yahoo.co.id
}

\begin{abstract}
Abstrak
Tujuan penelitian ini adalah untuk mengetahui efektivitas Badan Keamanan Laut dalam melaksanakan fungsi penegakan hukum di perairan laut Indonesia. Penelitian menggunakan pendekatan penelitian kualitatif. Informan penelitian sebanyak 9 orang ditentukan dengan snowball sampling. Pengumpulan data dilakukan dengan menggunakan teknik observasi, wawancara dan studi kepustakaan. Analisis data menggunakan analisis deskriptif yang dikembangkan dengan analisis triangulasi. Hasil penelitian menemukan bahwa Badan Keamanan Laut belum efektif dalam melaksanakan fungsi penegakan hukum di perairan laut Indonesia, hal ini disebabkan menurunnya pelaksanaan operasi Badan Keamanan Laut selama tahun anggaran 2018. Bila dibandingkan dengan kompleksitas tuntutan dan tantangan keamanan dan keselamatan perairan laut Indonesia yang luasnya mencapai lebih kurang 5,8 juta $\mathrm{km} 2$ dengan kondisi geografis negara kepulauan yang terdiri dari 17.054 pulau, maka efektivitas Badan Keamanan Laut dalam melaksanakan fungsi penegakan hukum di wilayah perairan laut Indonesia dan wilayah yuridiksi Indonesia perlu ditingkatkan. Konsep Baru yang didapat dari analisis efektivitas Badan Keamanan Laut dalam melaksanakan fungsi penegakan hukum di wilayah perairan laut Indonesia dan wilayah yuridiksi Indonesia adalah konsep baru tentang Manajemen Sarana Prasarana Keamanan Laut Indonesia.
\end{abstract}

Kata kunci: efektivitas, badan keamanan laut, penegakan hukum.

\begin{abstract}
The purpose of this study was to determine the effectiveness of the Maritime Security Agency in carrying out law enforcement functions in Indonesian marine waters. Research uses a qualitative research approach. 9 informants of the research were determined by snowball sampling. Data collection was carried out using observation, interview and literature study techniques. Data analysis using descriptive analysis developed with triangulation analysis. The results of the study found that the Maritime Security Agency has not been effective in carrying out law enforcement functions in Indonesian marine waters, this is due to the decreasing operation of the Maritime Security Agency during the 2018 budget year. less 5.8 million $\mathrm{km} 2$ with the geographical condition of an archipelago consisting of 17,054 islands, the effectiveness of the Maritime Security Agency in carrying out law enforcement functions in the territorial waters of Indonesia and Indonesia's jurisdiction needs to be improved. The new concept obtained from the analysis of the effectiveness of the Maritime Security Agency in carrying out law enforcement functions in the territorial waters of the Indonesian seas and the jurisdiction of Indonesia is a new concept about the Management of Facilities for Indonesia's Marine Security Infrastructure.
\end{abstract}

Keywords: effectiveness, marine security agency, law enforcement. 


\section{A. PENDAHULUAN}

Indonesia mengembangkan konsep wawasan nusantara dengan melihat Indonesia ke dalam politik kewilayahannya. Kewilayahan yang diperjuangkan telah diterima sebagai konsep wilayah nusantara dalam United Nations Convention on the Law of the Sea/UNCLOS 1982. Sejak itu semua politik kewilayahan Indonesia disesuaikan dengan ketentuan yang ada dalam UNCLOS, termasuk semua peraturan perundang-undangan ditinjau ulang dan disesuaikan dengan kepentingan Indonesia dan ketentuan UNCLOS. Berdasarkan UNCLOS 1982, Indonesia dalam menjalankan tugas dan fungsi kedaulatannya di Perairan Indonesia meliputi Perairan Pedalaman, Perairan Kepulauan, dan Laut Teritorial harus mengakomodasi kepentingan internasional khususnya lintas (pelayaran dan penerbangan) melalui perairan kepulauan dan laut teritorial Indonesia.

Menyadari bahwa wilayah laut sebagai bagian terbesar dari wilayah Indonesia yang memiliki posisi dan nilai strategis merupakan modal dasar pembangunan nasional, maka upaya pengelolaan sumber daya kelautan yang mencakup berbagai aspek kehidupan politik, ekonomi, sosial budaya, pertahanan, dan keamanan tentu perlu diselenggarakan secara terpola, terpadu, berkelanjutan dan melembaga dengan standar kebijakan dan tujuan yang jelas dan menyeluruh. Upaya pengelolaan sumber daya kelautan yang demikian itu merupakan pengejawantahan kedaulatan NKRI.

Karena itu, Negara Kesatuan Republik Indonesia berhak melakukan konservasi dan pengelolaan sumber daya hayati di laut lepas. Hak negara ini diselenggarakan oleh Pemerintah, dengan melaksanakan fungsi-fungsi pemerintahan yang terkait dengan upaya pengelolaan sumber daya kelautan sebagai salah satu modal dasar pembangunan nasional. Fungsi-fungsi pemerintahan yang dimaksud antara lain fungsi perlindungan, fungsi pertahanan, dan fungsi penegakkan hukum yang terkait dengan keamanan laut.

Dalam komteks itu, di laut lepas Pemerintah wajib: a). memberantas kejahatan internasional; b).memberantas siaran gelap; c). melindungi kapal nasional, baik di bidang teknis, administratif, maupun sosial; d). melakukan pengejaran seketika; e). mencegah dan menanggulangi Pencemaran Laut dengan bekerja sama dengan negara atau lembaga internasional terkait; dan f). berpartisipasi dalam pengelolaan perikanan melalui forum pengelolaan perikanan regional dan internasional (Undang-Undang No. 32 tahun 2014).

Penegakan kedaulatan dan hukum di perairan Indonesia, dasar Laut, dan tanah di bawahnya, termasuk kekayaan alam yang terkandung di dalamnya serta sanksi atas pelanggarannya dilaksanakan sesuai dengan ketentuan peraturan perundangundangan dan 
hukum internasional. Yurisdiksi dalam penegakan kedaulatan dan hukum terhadap kapal asing yang sedang melintasi laut teritorial dan perairan kepulauan Indonesia dilaksanakan sesuai dengan ketentuan peraturan perundang-undangan dan hukum internasional. Dalam rangka penegakan hukum di wilayah perairan dan wilayah yurisdiksi, khususnya dalam melaksanakan patroli keamanan dan keselamatan di wilayah perairan dan wilayah yurisdiksi Indonesia, dibentuk Badan Keamanan Laut (Undang-Undang No. 32 Tahun 2014).

Badan Keamanan Laut (Bakamla) merupakan lembaga pemerintah non kementerian yang berkedudukan di bawah dan bertanggung jawab langsung kepada Presiden melalui menteri yang mengoordinasikannya. Terhadap eksistensi Bakamla ini, maka tujuan penelitian ini adalah untuk mengetahui efektivitas Badan Keamanan Laut (Bakamla) dalam melaksanakan fungsi penegakan hukum di perairan laut Indonesia.

\section{B. KERANGKA TEORI}

Siagian (1995), menunjukkan efektivitas organisasi yang meliputi: (1) Kejelasan tujuan yang hendak dicapai; (2) Kejelasan strategi pencapaian tujuan; (3) Proses analisa dan perumusan kebijakan yang mantap; (4) Perencanaan yang matang; (5) Penyusunan Program yang Tepat; (6) Tersedianya sarana dan prasarana kerja; (7) Pelaksanaan yang efektif dan efisien; dan (8) Sistem pengawasan dan pengendalian yang bersifat mendidik.

Efektivitas BAKAMLA dalam melaksanakan fungsi penegakkan hukum di perairan laut Indonesia adalah keberhasilan atau pencapaian tujuan pelaksanaan kebijakan dan kegiatan operasional penjagaan, pengawasan, pencegahan, dan penindakan pelanggaran hukum di wilayah perairan laut Indonesia dan wilayah yurisdiksi Indonesia yang terungkap dari (1) kejelasan tujuan yang hendak dicapai, (2) kejelasan strategi pencapaian tujuan, (3) proses analisa dan perumusan kebijakan yang mantap, (4) perencanaan yang matang, (5) penyusunan program yang tepat, (6) tersedianya sarana dan prasarana kerja, (7) pelaksanaan yang efektif dan efisien, (8) sistem pengawasan dan pengendalian.

Dari definisi konspetual tersebut dikembangkan 8 dimensi analisis: (1) Analisis kejelasan tujuan yang hendak dicapai, (2) Analisis kejelasan strategi pencapaian tujuan, (3) Analisis proses perumusan kebijakan, (4) Analisis perencanaan, (5) Analisis penyusunan program, (6) Analisis sarana dan prasarana kerja, (7) Analisis pelaksanaan yang efektif dan efisien, dan (8) Analisis sistem pengawasan dan pengendalian. 


\section{METODE}

Penelitian menggunakan pendekatan penelitian kualitatif yang dirancang dengan paradigma post positivis (Creswell, 1994). Informan penelitian sebanyak 9 orang ditentukan dengan snow ball technique. Pengumpulan data sekunder menggunakan studi kepustakaan; pengumpulan data primer menggunakan teknik wawancara dan observasi; wawancara dilakukan dengan Pedoman Wawancara yang disusun menurut konstruk teori efektivitas organisasi Siagian. Analisis data dilakukan secara deskriptif dengan metode triangulasi.

\section{HASIL DAN PEMBAHASAN}

Hasil wawancara dengan 9 Informan Penelitian dibahas menurut teori efektivitas organisasi Siagian untuk mengetahui kondisi obyektif 9 parameter efektivitas keorganisasian Bakamla. Pembahasan dilakukan dengan merujuk data fungsional dan data faktual. Stand Point masing-masing parameter adalah berikut:

Dari analisis deskriptif kejelasan tujuan yang hendak dicapai diperoleh suatu gambaran konseptual bahwa Bakamla sudah cukup maksimal dalam mendeskripsikan kejelasan tujuan yang hendak dicapai dalam menjabarkan Undang-Undang Nomor 32 Tahun 2014 tentang Kelautan dan melaksanakan Peraturan Presiden Nomor 2 Tahun 2015 tentang Badan Keamanan Laut. Kejelasan tujuan yang hendak dicapai tersebut terdeskripsikan dalam (1) penyusunan kebijakan nasional di bidang keamanan dan keselamatan di wilayah perairan Indonesia dan wilayah yurisdiksi Indonesia; (2) penyelenggaraan sistem peringatan dini keamanan dan keselamatan di wilayah perairan Indonesia dan wilayah yurisdiksi Indonesia; (3) operasi penjagaan, pengawasan, pencegahan, dan penindakan pelanggaran hukum di wilayah perairan Indonesia dan wilayah yurisdiksi Indonesia; (4) sinergitas dan memonitoring pelaksanaan patroli perairan oleh instansi terkait; (5) pemberian dukungan teknis dan operasional kepada instansi terkait; dan (6) pemberian bantuan pencarian dan pertolongan di wilayah perairan Indonesia dan wilayah yurisdiksi Indonesia.

Kejelasan tujuan yang hendai dicapai Bakamla dalam melaksanakan fungsi penegakan hukum di wilayah perairan laut Indonesia dan wilayah yuridiksi Indonesia untuk kurun waktu 25 tahun mendatang ditetapkan dengan Keputusan Keala Badan Keamanan Laut Nomor 84 Tahun 2018 tentang Grand Design Badan Keamanan Laut Republik Indonesia Tahun 2019-2045. Dalam Grand Design dinyatakan bahwa visi Bakamla, sebagai lembaga pemerintah yang diberikan mandat untuk mengkoordinasikan serta menjaga keamanan laut di wilayah Indonesia, adalah: "Terjaminnya keamanan dan keselamatan laut yang terpercaya 
dan profesional sesuai dengan kebijakan Nasional dan Internasional guna mendukung terciptanya Indonesia yang berdaulat, mandiri dan sejahtera". Misi Bakamla yang telah ditetapkan adalah peran strategis yang diinginkan dalam mencapai visi. Rumusan misi yang kemudian telah disinergikan dengan tugas dan fungsi Bakamla yang baru ini adalah sebagai berikut: 1. Menjaga keamanan dan keselamatan di wilayah perairan Indonesia, wilayah yuridiksi Indonesia dan kawasan dengan berpedoman pada ketentuan hukum nasional dan internasional; 2. Menjaga pemanfaatan dan kelestarian sumber daya laut demi tercapainya kesejahteraan nasional; 3. Menjaga kedaulatan dan kemandirian Indonesia sebagai negara kepulauan terbesar di dunia; dan 4. Mendorong kemampuan Indonesia untuk menjadi poros maritim dunia yang mandiri dan kuat berbasiskan kepentingan Nasional.

Dengan visi dan misi yang telah diuraikan sebelumnya, Badan Keamanan Laut juga memiliki tujuan baru, yakni sebagai berikut: "Pembangunan sistem keamanan dan keselamatan maritim, dengan peningkatan sistem pengawasan, penegakan hukum dan sistem informasi kemaritiman di wilayah perairan Indonesia dan wilayah yurisdiksi Indonesia secara terintegrasi dan terpercaya."

Dari analisis deskriptif kejelasan strategi pencapaian tujuan diperoleh suatu gambaran konseptual bahwa Bakamla sudah cukup maksimal dalam mendeskripsikan kejelasan strategi pencapaian tujuan mengimplementasikan Undang-Undang Nomor 32 Tahun 2014 tentang Kelautan dan melaksanakan Peraturan Presiden Nomor 2 Tahun 2015 tentang Badan Keamanan Laut. Kejelasan strategi ini sudah terdeskripsi dalam penyusunan Grand Design Bakamla Tahun 2019-2045 dengan memberikan pernyataan rencana strategis dan peran strategis Bakamla.

Rencana Strategis Bakamla : Merujuk dari visi dan misi Bakamla sebagai institusi professional dan dapat dipercaya masyarakat, dan secara khusus misi Bakamla untuk menjaga keamanan dan kedaulatan laut wilayah Indonesia, maka diperlukan rencana strategis kedepan untuk membuat kinerja Bakamla lebih baik dan optimal. Grand Design Bakamla diperlukan untuk memberikan arah kebijakan pengelolaan keamanan dan keselamatan laut di wilayah perairan dan wilayah yurisdiksi Indonesia, agar dapat berjalan efektif, efisien, terukur, konsisten, terintegrasi dan berkelanjutan, maka diperlukan rencana strategis dalam kurun waktu tahun 2019-2045. Adapun rencana strategis dalam kurun waktu tersebut adalah sebagai berikut: (1) Terbentuknya kebijakan nasional di bidang keamanan dan keselamatan di wilayah perairan Indonesia dan wilayah yurisdiksi Indonesia; (2) Terciptanya pengawasan dan penegakan hukum di wilayah perairan dan wilayah yurisdiksi Indonesia secara terpadu; 
(3) Terwujudnya sistem informasi maritim di wilayah perairan indonesia dan wilayah yurisdiksi Indonesia yang terintegrasi; (4) Terwujudnya kapasitas lembaga keamanan laut yang efisien, efektif dan terpercaya; (5) Terwujudnya kapasitas sumber daya manusia aparatur keamanan laut yang profesional, berkompetensi global dan terpercaya; dan (6) Terpenuhinya sarana dan prasarana keamanan dan keselamatan laut yang handal dan modern.

Peran Strategis Bakamla: Peningkatan yang ingin dicapai dalam rangka peningkatan keamanan, keselamatan, penegakan hukum dan sistem peringatan dini keamanan dan keselamatan di wilayah perairan Indonesia dan wilayah yurisdiksi Indonesia secara tersinergi guna tercapainya Indonesia menjadi Negara maritim yang mandiri, maju, kuat, dan berbasiskan kepentingan nasional, rencana strategis yang telah disebutkan melahirkan peranan strategis, yaitu: (1) Meningkatnya penegakan hukum di wilayah perairan Indonesia dan wilayah yurisdiksi Indonesia secara terpadu; (2) Meningkatnya kebijakan nasional di bidang keamanan dan keselamatan di wilayah perairan Indonesia dan wilayah yurisdiksi Indonesia yang kredibel; (3) Mewujudkan sistem informasi/sistem peringatan dini keamanan dan keselamatan di wilayah perairan Indonesia dan wilayah yurisdiksi Indonesia yang terintegrasi Meningkatnya kapasitas kelembagaan keamanan laut yang efisien dan modern; (4) Meningkatnya kapasitas sumber daya manusia (SDM) aparatur keamanan laut yang profesional, berkompetensi tinggi non sektoral; (5) Meningkatnya sarana dan prasarana keamanan dan keselamatan laut yang handal dan modern berbasis sistem peringatan dini Meningkatnya penegakan hukum di wilayah perairan Indonesia dan wilayah yurisdiksi Indonesia secara terpadu; (6) Meningkatnya kebijakan nasional di bidang keamanan dan keselamatan di wilayah perairan indonesia dan wilayah yurisdiksi indonesia yang kredibel; (7) Mewujudkan sistem informasi/sistem peringatan dini keamanan dan keselamatan di wilayah perairan indonesia dan wilayah yurisdiksi indonesia yang terintegrasi; (8) Meningkatnya kapasitas kelembagaan keamanan laut yang efisien dan modern; (9) Meningkatnya kapasitas sumber daya manusia (SDM) aparatur keamanan laut yang professional, berkompetensi tinggi non sektoral; dan (10) Meningkatnya sarana dan prasarana keamanan dan keselamatan laut yang handal dan modern berbasis sistem peringatan dini.

Dari analisis deskriptif kejelasan perumusan kebijakan diperoleh suatu gambaran konseptual bahwa Bakamla sudah cukup maksimal dalam mendeskripsikan kejelasan perumusan kebijakan organisasional dalam mengimplementasikan Undang-Undang Nomor 32 Tahun 2014 tentang Kelautan dan melaksanakan Peraturan Presiden Nomor 2 Tahun 2015 tentang Badan Keamanan Laut. Kejelasan perumusan kebijakan organisasional yang 
dimaksud sudah terdeskripsi dalam penyusunan Grand Design Bakamla Tahun 2019-2045. Grand Design BAKAMLA merupakan konsep induk dari suatu skema/garis besar rencana pembaruan dan pengembangan BAKAMLA secara holistik dan komprehensif agar BAKAMLA memiliki eksistensi yang kuat untuk dapat mengantisipasi berbagai tantangan dimasa kini dan dimasa depan. Grand Design BAKAMLA disusun untuk jangka waktu 20192045, yang dijabarkan dalam kerangka pengembangan organisasi, sumber daya manusia, serta teknologi dan sarana prasarana. Visi Bakamla, sebagai lembaga pemerintah yang diberikan mandat untuk mengkoordinasikan serta menjaga keamanan laut di wilayah Indonesia, adalah: "Terjaminnya keamanan dan keselamatan laut yang terpercaya dan profesional sesuai dengan kebijakan Nasional dan Internasional guna mendukung terciptanya Indonesia yang berdaulat, mandiri dan sejahtera."

Misi Bakamla yang telah ditetapkan adalah peran strategis yang diinginkan dalam mencapai Visi. Rumusan misi yang kemudian telah disinergikan dengan tugas dan fungsi Bakamla yang baru ini adalah sebagai berikut: (1) Menjaga keamanan dan keselamatan di wilayah perairan Indonesia, wilayah yuridiksi Indonesia dan kawasan dengan berpedoman pada ketentuan hukum nasional dan internasional; (2) Menjaga pemanfaatan dan kelestarian sumber daya laut demi tercapainya kesejahteraan nasional; (3) Menjaga kedaulatan dan kemandirian Indonesia sebagai negara kepulauan terbesar di dunia; dan (4) Mendorong kemampuan Indonesia untuk menjadi poros maritim dunia yang mandiri dan kuat berbasiskan kepentingan Nasional. Dengan visi dan misi yang telah diuraikan sebelumnya, Badan Keamanan Laut juga memiliki tujuan baru, yakni sebagai berikut: "Pembangunan sistem keamanan dan keselamatan maritim, dengan peningkatan sistem pengawasan, penegakan hukum dan sistem informasi kemaritiman di wilayah perairan Indonesia dan wilayah yurisdiksi Indonesia secara terintegrasi dan terpercaya".

Dari analisis deskriptif perencanaan diperoleh suatu gambaran faktual bahwa Bakamla sudah cukup optimal dalam menyusun perencanaan program dan anggaran untuk mencapai sasaran strategis pelaksanaan tugas dan fungsi untuk satu tahun anggaran. Namun perencanaan program dan anggaran tersebut tidak melebihi pagu anggaran yang disediakan oleh pemerintah. Artinya, efektivitas Bakamla dalam melaksanakan fungsi penegakan hukum terbatas menurut kebijakan alokasi anggaran dari pemerintah. Oleh sebab itu, Bakamla belum optimal dalam mengimplementasikan Undang-Undang Nomor 32 Tahun 2014 tentang Kelautan. Meskipun begitu, Bakamla telah memiliki suatu sistem perencanaan untuk 25 tahun mendatang. Sistem perencanaan yang dimaksud adalah Grand Design Bakamla Tahun 
2019-2045. Grand Design Bakamla merupakan konsep induk suatu skema/garis besar rencana pembaruan dan pengembangan Bakamla secara holistik dan komprehensif agar Bakamla memiliki eksistensi yang kuat untuk dapat mengantisipasi berbagai tantangan dimasa kini dan dimasa depan. Grand Design Bakamla disusun untuk jangka waktu 20192045, yang dijabarkan dalam kerangka pengembangan organisasi, sumber daya manusia, serta teknologi dan sarana prasarana. Tujuan penjabaran tersebut adalah membangun sistem keamanan dan keselamatan maritim, dengan peningkatan sistem pengawasan, penegakan hukum dan sistem informasi kemaritiman di wilayah perairan Indonesia dan wilayah yurisdiksi Indonesia secara terintegrasi dan terpercaya.

Dari analisis deskriptif penyusunan program diperoleh suatu gambaran faktual bahwa secara manajerial Bakamla sudah menyusun dan melaksanakan berbagai program untuk mengoptimalkan pelaksanaan fungsi penegakan hukum di wilayah perairan laut Indonesia dan wilayah yuridiksi Indonesia. Penyusunan dan pelaksanaan program yang dimaksud pada tahun anggaran 2018 meliputi program Sekretariat Utama; program Deputi Bidang Operasi dan Latihan; program Deputi Bidang Kebijakan dan Strategi; program Deputi Bidang Informasi, Hukum dan Kerjasama. Pelaksanaan fungsi penegakan hukum oleh Bakamla belum optimal karena pelaksanaan program Bakamla dihadapkan pada rumitnya permasalahan tumpang tindih kewenangan dan ego sektoral para pemangku kepentingan. Meskipun begitu, Bakamla telah memiliki suatu sistem perencanaan untuk 25 tahun mendatang. Sistem perencanaan yang dimaksud adalah Grand Design Bakamla Tahun 20192045. Penyusunan Grand Design Bakamla tersebut mencakup berbagai program pengembangan organisasi, sumber daya manusia, serta teknologi dan sarana prasarana dengan tujuan membangun sistem keamanan dan keselamatan maritim, dengan peningkatan sistem pengawasan, penegakan hukum dan sistem informasi kemaritiman di wilayah perairan Indonesia dan wilayah yurisdiksi Indonesia secara terintegrasi dan terpercaya.

Dari analisis deskriptif ketersediaan sarana dan prasarana kerja Bakamla diperoleh suatu gambaran faktual bahwa untuk menjadi leading sector penyelenggaraan sistem keamanan dan keselamatan di perairan laut Indonesia dan wilayah yuridiksi Indonesia Bakamla membutuhkan 255 unit kapal patroli yang terdiri atas : 3 Kapal Induk 110 meter; 6 Kapal Patroli 80 meter, 122 Kapal Patroli 48 meter, dan 124 Kapal Interceptor. Bila dibandingkan dengan jumlah kapal patroli yang dimiliki Bakamla yang hanya mencapai 25 kapal patroli dengan kondisi sebagian kapal tidak siap operasi, maka dapat dinyatakan bahwa Bakamla hanya mempunyai 9,80 persen dari total kebutuhan kapal patroli yang harus 
dimilikinya. Dengan kondisi sarana prasarana operasional yang demikian itu Bakamla tentu sulit mengoptimalkan pelaksanaan fungsi penegakan hukum di perairan laut Indonesia dan wilayah yuridiksi Indonesia secara efektif. Terlebih lagi dengan rumitnya permasalahan tumpang tindih kewenangan dan ego sektoral maka dengan sendirinya eksistensi Bakamla menjadi tidak optimal untuk menjadi leading sector penyelenggaraan sistem keamanan dan keselamatan laut Indonesia.

Dari analisis deskriptif pelaksanaan yang efektif dan efisien diperoleh suatu gambaran faktual bahwa implementasi berbagai kebijakan, program dan kegiatan operasional Bakamla tidak hanya dihadapkan pada keterbatasan sumber daya namun Bakamla juga dihadapkan pada sulitnya menjadi leading sector dalam penyelenggaraan sistem keamanan dan keselamatan di wilayah perairan laut Indonesia dan wilayah yuridiksi Indonesia. Salah satu komponen keterbatasan sumber daya yang paling menonjol dan berpengaruh pada efektivitas dan efisiensi adalah bahwa Bakamla hanya memiliki 9,80 persen dari total kebutuhan kapal patroli untuk melakukan operasi pengamanan dan penyelamatan di seluruh zona maritim yang mencapai 255 kapal patroli yang terdiri dari berbagai jenis dan kapasitas operasi. Bakamla tidak hanya dihadapkan pada keterbatasan sumber daya namun Bakamla juga dihadapkan pada permasalahan tumpang tindih kewenangan dan benturan kepentingan sektoral yang menyebabkan Bakamla sulit menjadi leading sector dalam penyelenggaraan sistem keamanan dan keselamatan di laut. Dengan situasi dan kondisi yang demikian itu maka efektivitas Bakamla dalam melaksanakan fungsi penegakan hukum di wilayah perairan laut Indonesia dan wilayah yuridiksi Indonesia menjadi tidak optimal.

Dari analisis deskriptif sistem pengawasan dan pengendalian diperoleh suatu gambaran faktual bahwa dalam lingkup internal Bakamla pelaksanaan fungsi pengawasan dan pengendalian dilakukan oleh inspektorat. Namun pelaksanaan fungsi Inspektorat tersebut belum efektif karena pada tahun anggaran 2016 dan 2017 Bakamla mendapatkan penilaian Disclaimer dari Badan Pemeriksa Keuangan. Dalam lingkup eksternal Bakamla, kinerja pengawasan dan pengendalian terhadap kegiatan illegal di wilayah perairan laut Indonesia dan wilayah yuridiksi Indonesia yang dilakukan Bakamla belum optimal, karena luasnya wilayah perairan, kondisi geografis, sarana dan prasarana yang sangat terbatas, sumber daya manusia juga terbatas, adanya wilayah perbatasan jarak beberapa negara tetangga yang berdekatan dan perkembangan teknologi yang pesat sehingga Bakamla seringkali tertingal dalam hal teknologi dengan negara tetangga seperti Singapura. Salah satu komponen keterbatasan sarana prasarana yang paling menonjol dan berpengaruh pada efektivitas 
pengawasan dan pengendalian kegiatan illegal di wilaya perairan laut Indonesia dan wilayah yuridiksi Indonesia adalah bahwa Bakamla hanya memiliki 9,80 persen dari total kebutuhan kapal patroli untuk melakukan operasi pengawasan dan pengendalian di seluruh zona maritim yang mencapai 255 kapal patroli terdiri dari berbagai jenis dan kapasitas operasional.

Konsep Baru yang didapat dari pembahasan efektivitas Bakamla dalam melaksanakan fungsi penegakan hukum di wilayah perairan laut Indonesia dan wilayah yuridiksi Indonesia adalah konsep baru tentang Manajemen Sarana Prasarana Keamanan Laut Indonesia. Manajemen Sarana Prasarana Keamanan Laut Indonesia adalah sistem tata kelola kapal patroli dan fasilitas pendukung yang diselenggarakan Badan Keamanan Laut guna mengoptimalkan pelaksanaan fungsi peringatan dini; operasi pengamanan dan penyelamatan; operasi pencarian dan pertolongan di wilayah perairan laut Indonesia dan wilayah yurisdiksi Indonesia yang meliputi perencanaan, Pengadaan, Penggunaan, dan Pemanfaatan, Pemeliharaan dan Perbaikan, Penghapusan dan Pemindatanganan.

Berdasarkan deskripsi Konsep Baru tersusun Proposisi hasil penelitian sebagai berikut: Perencanaan, Pengadaan, Penggunaan dan Pemanfaatan, Pemeliharaan dan Perbaikan, Penghapusan dan Pemindahtanganan kapal patroli dan fasilitas pendukung menentukan efektivitas Badan Keamana Laut dalam melaksanakan fungsi penegakan hukum di wilayah perairan laut Indonesia dan wilayah yuridiksi Indonesia.

\section{E. KESIMPULAN}

Badan Keamanan Laut (Bakamla) belum efektif dalam melaksanakan fungsi penegakan hukum di perairan laut Indonesia, karena hanya mampu mencapai kinerja 60\% dari target awal 70\% dan berperan hanya sebesar 8,41\% dalam proses penegakan hukum di perairan laut Indonesia dengan jumlah 27 perkara. Hal tersebut disebabkan oleh menurunnya pelaksanaan operasi Bakamla selama tahun anggaran 2018 yang dibatasi oleh ketersediaan anggaran. Bila dibandingkan dengan kompleksitas tuntutan dan tantangan keamanan dan keselamatan perairan laut Indonesia yang luasnya mencapai lebih kurang 5,8 juta km2 dengan kondisi geografis negara kepulauan yang terdiri dari 17.054 pulau yang telah teridentifikasi, maka efektivitas Bakamla dalam melaksanakan fungsi penegakan hukum di wilayah perairan laut Indonesia dan wilayah yuridiksi Indonesia secara bertahap dan berkelanjutan perlu ditingkatkan.

Konsep Baru yang didapat dari pembahasan efektivitas Bakamla dalam melaksanakan fungsi penegakan hukum di wilayah perairan laut Indonesia dan wilayah yuridiksi Indonesia 
adalah konsep tentang Manajemen Sarana Prasarana Keamanan Laut Indonesia. Manajemen

Sarana Prasarana Keamanan Laut Indonesia adalah sistem tata kelola kapal patroli dan fasilitas pendukung yang diselenggarakan Badan Keamanan Laut guna mengoptimalkan pelaksanaan fungsi peringatan dini; operasi pengamanan dan penyelamatan; operasi pencarian dan pertolongan di wilayah perairan laut Indonesia dan wilayah yurisdiksi Indonesia yang meliputi perencanaan, Pengadaan, Penggunaan, dan Pemanfaatan, Pemeliharaan dan Perbaikan, Penghapusan dan Pemindatanganan.

\section{DAFTAR PUSTAKA}

Creswel, J. W. (1994). Research Design Qualitative \& Quantitative Approaches. New Delhi: Sage Publication.

Coff, R. W. (1997). Human Assets and Management Dilemmas: Coping with Hazards on the Road to Resource-Based Theory. Academy of management review, 22(2), 374-402.

Nahapiet, J., \& Ghoshal, S. (1998). Social Capital, Intellectual Capital, and the Organizational Advantage. Academy of Management Review, 23(2), 242-266.

Davis, K., \& Newstrom, J. W. (1998). Perilaku dalam Organisasi (terjemahan: Agus Dharma). Jakarta: Erlangga.

Daft, R. L. (1992). Organization Theory and Design. USA: West Publising Company.

Dessler, G. (1997). Manajemen Personalia (terjemahan: Agus Dharma). Jakarta: Erlangga.

Ganon, M. J. (1979). Organization Behavior. Boston: Littlr Brown and Company.

George, J. M., Jones, G. R., \& Sharbrough, W. C. (2005). Understanding and managing organizational behavior. Upper Saddle River, NJ: Pearson Prentice Hall.

Gibson, J. L., Ivancevich, J. M., \& Donnelly, J. H. (1996). Organisasi: Perilaku, Struktur dan Proses. Bina Rupa Aksara. Jakarta.

Gibson, J. L., Ivancevich, J. M., Donnelly, J. H., \& Konopaske, R. (2006). Organizations: Behavior, structure, processes. Homewood, IL: Irwin.

Gilley, J. W., \& Maycunich, A. (2000). Organizational learning, performance and change. Da Capo Press.

Gordon, J. R. (1993). A Diagnostic Approach to Organizational Behaviour. Boston: Allyn and Bacon.

Hardjito, D. (2001). Organisasi dan Teknik Pengorganisasian. Jakarta: Raja Grafindo Persada.

Hersey, P., \& Blanchart, K. H. (1995). Manajemen Perilaku Organisasi: Pendayagunaan Sumber Daya Manusia (terjemahan Agus Dharma). Jakarta: Erlangga.

Master Plan Kebutuhan Kapal Patroli Untuk Pengamanan Wilayah Yuridiksi dan Perairan Indonesia, Kerjasama Bakamla dan Universitas Indonesia, 2018.

Robbins, S. P. (1994). Teori Organisasi: Struktur, Desain dan Aplikasi. Jakarta: Arcan.

JURNAL PAPATUNG: Vol. 2 No. 3 Tahun 2019 
Robbins, S. P. (2002). Prinsip-Prinsip Perilaku Organisasi. Jakarta: Erlangga.

Schein, E. H. (1991). Psikologi Organisasi. Jakarta: Pustaka Binaman Pressindo.

Schermerhorn, J. R., Hunt, J. G., \& Osborn, R. N. (1987). Managing Organizational Behavior. New York: John Wiley \& Sons Inc.

Scott, W. G. (1989). Organization Theory an Overview and Appraisal: Management and Organizational Behavioural Classics. Illinois: Homewood.

Siagian, S. P. (1983). Bunga Rampai Manajemen Modern. Jakarta: Toko Gunung Agung.

Steers, R. M. (1985). Efektivitas Organisasi. Jakarta: Erlangga.

Stooner, J. A., \& Freeman, F. R. E. (1992). Organization Effectivity. Jakarta: Erlangga

Sluyter, G. V. (1998). Improving Organizational Performance: A Practice Guide for The Human Service Field. New York: Printed in The United States of America. 